http://jmscr.igmpublication.org/home/ ISSN (e)-2347-176x ISSN (p) 2455-0450 crossref DOI: https://dx.doi.org/10.18535/jmscr/v8i6.86

\title{
Sturge-Weber Syndrome a Rare Neurocutaneous Syndrome Presenting As Open Angle Glaucoma: A Care Report
}

\author{
Authors \\ Nishant Acharya1, Priyanka Sharma ${ }^{2 *}$ \\ ${ }^{1}$ Department of Paediatrics, Dr. RKGMC Hamirpur (H.P), India \\ ${ }^{2}$ Department of OBG, Bhandari Hospital Hamirpur (H.P), India \\ *Corresponding Author \\ Priyanka Sharma
}

\begin{abstract}
Sturge-Weber syndrome (SWS) is a rare congenital neurocutaneous syndrome is characterized by unilateral facial cutaneous vascular malformations affecting the eye and skin in association with ipsilateral leptomeningeal angiomatosis. The incidence of SWS is 1:50,000 infants, with no predilection for the sex. Glaucoma in SWS patients shows a bimodal peak of age development: an early-onset (congenital) form affecting $\sim 60 \%$ of patients and a late onset form during childhood and adolescence (40\% of cases). Association of glaucoma with SWS is unilateral, most frequently as open-angle glaucoma leading to progressive visual field loss. Our case illustrated the need of regular follow up and early intervention in the patients with cutaneous port wine stain (PWS) in the distribution of trigeminal nerve to prevent loss of vision due to glaucoma.
\end{abstract}

Keywords: Struge weber syndrome, Port wine strain, Glaucoma, Leptomeningeal angiomatosis.

\section{Introduction}

Sturge-Weber syndrome (SWS) or encephalotrigeminal angiomatosis belongs to a group of disorders termed as phakomatoses. This rare congenital neurocutaneous syndrome is characterized by unilateral facial cutaneous vascular malformations affecting the eye and skin in association with ipsilateral leptomeningeal angiomatosis $^{[1]}$. The syndrome was first identified by Schirmer, in 1860, and later further described it in detail by Sturge in 1879. Frederick Parkes Weber in 1992 demonstrated intracranial calcification. The incidence of SWS is 1:50,000 infants, with no predilection for the $\operatorname{sex}^{[2]}$. Several genes in the $17 \mathrm{p} 1-\mathrm{p} 13$ region, are implicated in SWS, are also known to be linked to some rare abnormalities and syndromes, like retinitis pigmentosa, cerebral astrocytoma, subglottic stenosis, KlippelTrenaunay-Weber syndrome, and phakomatosis pigmentovascularis $^{[3],[4],[5],[6],[7]}$. No hereditary pattern has been demonstrated. Embryologically SWS has been reported to be related to an impaired development of the cell precursors in the neural crest during the first trimester, resulting in the characteristic malformations observed in the central nervous system, skin, and eyes, all are being ectodermal in origin. Our case the patient presented to us with glucoma in adolescence age but it might have manifested in infancy as cornea was enlarged in the affected eye and the visual loss was already present with advanced glaucomatous field defect. 
This illustrates the need of regular follow up and early intervention in the patients with cutaneous port wine stain (PWS) in the distribution of trigeminal nerve to prevent loss of vision due to glaucoma.

\section{Case Report}

An eleven year girl presented in the paediatric outpatient department with acute unilateral left sided headache for the past 2 week. The headache was dull aching, episodic and responding well to the analgesic. On examination, the patient had unilateral PWS involving left forehead, left eyes (both upper and lower lid), left side of the nose, and left upper lip extending up to midline in the dermatological distribution of trigeminal nerve (Figure 1). On ocular examination Visual acuity was normal, however left eye revealed episceral congestion. The episceral veins were dilated and tortuous. The cornea was enlarged with vertical and horizontal diameters each of $13 \mathrm{~mm}$. Rest of anterior segment examination was normal. On examination of the posterior segment, there was gross disparity in the cup disc ratio, being 0.3 in the right eye while 0.7 in the left eye, with marked thinning and inferior notching of neuroretinal rim. IOP was raised 35.4 $\mathrm{mm}$ of $\mathrm{Hg}$ in the left eye compared to $22.4 \mathrm{~mm} \mathrm{Hg}$ in right eye. Visual field examination with Humpherys perimeter revealed corresponding advanced glaucomatous field defect in left eye. On gonioscopy, angle was open Schaffers grade IV in both eyes but left eye revealed vascular formations in trabecular meshwork.

Contrast enhanced computed tomography was further done to rule out intra -cranial pathology which revealed hypertrophy of choroid plexusus along with contrast enhancement (Figure 2). Rest of systemic examination was normal. In view of characteristic triad of ocular and dermatological signs with distinct radiological finding the diagnosis of SWS was established. Patient was put on topical antiglaucoma medication (Dorzolamide and Timolol combination). IOP was monitored on long term follow up, which gradually normalized $22.4 \mathrm{~mm} \mathrm{Hg}$ on day 7 and $17.3 \mathrm{~mm} \mathrm{Hg}$ on day 14 .

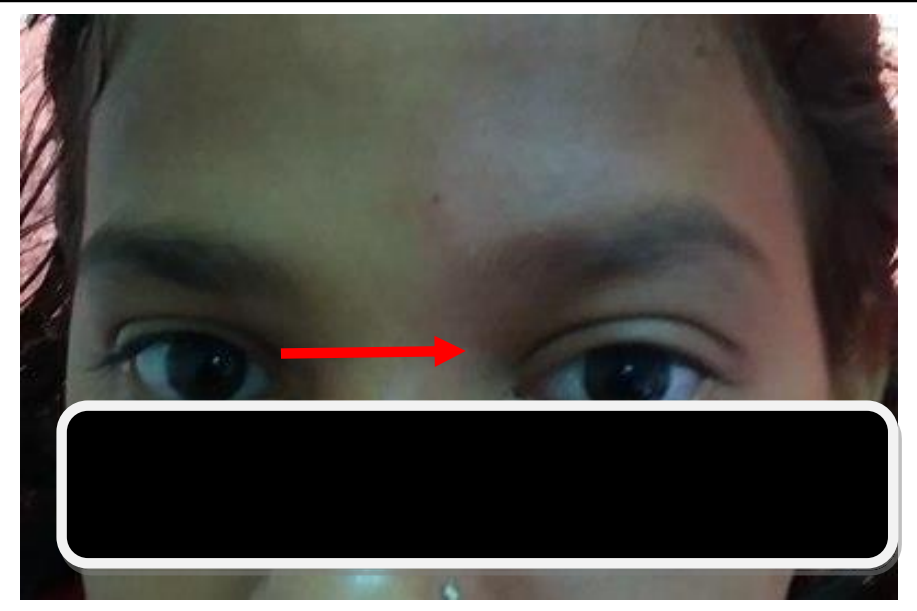

Fig. 1(a) Port wine stain

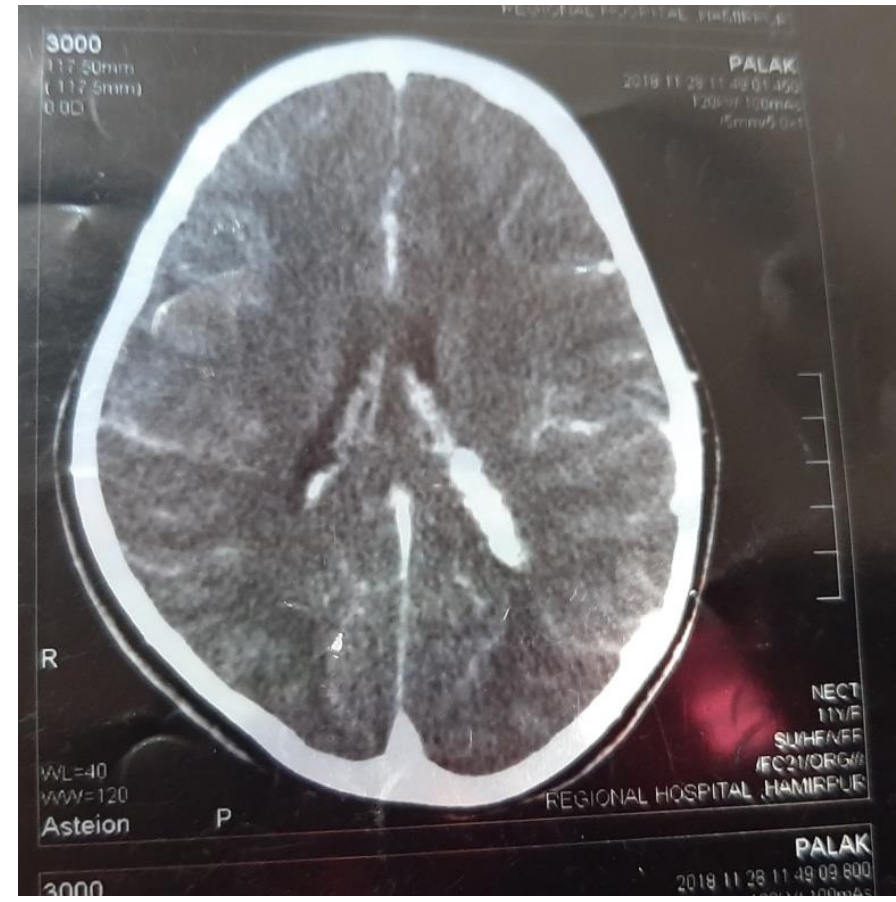

(b) CECT showing hypertrophy of choroid plexusus

\section{Discussion}

SWS is a sporadic congenital but not an inherited disease. It belongs to a group of neurocutaneous syndromes along with vascular malformations resulting from the failure of fetal veins to develop normally. These result in changes in the brain, skin and eye. According to Roach Scale classification, SWS is classified into four types (Table 1$)^{[8]}$ :

1) Presence of brain and facial angioma, with or without
glaucoma.
2) PWS without brain involvement, with or without
glaucoma.
3) Isolated brain angioma, usually without glaucoma.
4) Type 1 associated with systemic manifestation such as
tuberous sclerosis.

As per classification reported case belongs to Type I. 
Approximately $50 \%$ of SWS patients show pathologic ocular changes, usually ipsilateral to the PWS, involving the eyelid, anterior chamber, cornea, choroid, and retina. The presence of PWS may involve the eyelid and trigger pathological alterations in the ocular blood flow. Episcleral vessel dilatation can be observed in approximately half of SWS patients ${ }^{[9]}$. In our case there was involvement of both upper and lower lid along with dilatation of episcleral vessel.

Several anterior chamber changes have been described in SWS including vascular formations in the trabecular mesh-work near the scleral spur surrounded by large homogeneous extracellular matrix. We have also observed vascular formation in the trabecular meshwork.

Glaucoma in SWS patients shows a bimodal peak of age development: an early-onset (congenital) form affecting $\sim 60 \%$ of patients and a late onset form during childhood and adolescence (40\% of cases) [10]. Association of glaucoma with SWS is unilateral. It is more frequently associated (72\%) if both the eyelids are involved than if only upper eyelid $(21 \%)$ is involved ${ }^{[11]}$. The most frequent form of glaucoma in SWS patients is open-angle glaucoma leading to progressive visual field loss. In our case, though the patient presented to us with glucoma in adolescence age but it might have manifested in infancy as cornea was enlarged in the affected eye. The posterior segment of the eye is also involved with hemangiomas of the choroid $(20 \%-70 \% \text { of cases })^{[12]}$. Posterior segment was normal in present case. Radiological feature of Struge Webber syndrome include subcortical tram track pattern of calcification, parenchymal volume loss, enlarged choroid plexus and calvarial hyperostosis. Only enlargement of choroid plexus was present in our case.

\section{Conclusion}

The wide spectrum of clinical manifestation of SWS leads to multidisciplinary approaches for its management such as ophthalmologist, dermatologist and neurologist. The large spectrum of clinical manifestations of SWS shows its multifactorial nature and difficulty in diagnosis. As the exact etiopathogenesis is not known, hence its early diagnosis is crucial, to control of future complications. As glaucoma occur in about half of patients, so this article brings in light one of this rare entity, an early diagnosis of which may help in improving the quality of life by early detection and its treatment .In SWS, glaucoma can be present at birth, but the disease can also develop during childhood and in adults. Every child, adolescent as well as adult with port wine stain along dermatological distribution of trigeminal nerve should undergo complete ophthalmic examination, so blindness can be prevented by early detection and management of complications.

\section{References}

1. Z. Jing, L. Nan-yan, Z. Xiao-jun, W. Jiandong, M. A. Henghui, and Z. Ru-song, "Sturge-Weber syndrome:a case report and review of literatures," Chinese Medical Journal, vol. 123, no. 1, pp.117-121, 2010.

2. Welty LD. Sturge-Weber syndrome: A case study. Neonatal Netw 2006; 25: 89-98.

3. Comi AM, Mehta P, Hatfield LA, Dowling MM. Sturge-Weber syndrome associated with other abnormalities: a medical record and literature review. Arch Neurol. 2005; 62: 1924-1927.

4. Lee CW, Choi DY, Oh YG, Yoon HS, Kim JD. An infantile case of Sturge-Weber syndrome in association with KlippelTrenaunay-Weber syndrome and phakomatosis pigmentovascularis. J Korean Med Sci. 2005; 20: 1082-1084.

5. Sonmez FM, Aksoy A, Sari A, Erpolat S, Ozkaya AK. Phacomatosis pigmentovascularis type IIB associated with Sturge-Weber syndrome: a case report and review of the literature. Genet Couns. 2013; 24: 247-250.

6. Recupero SM, Abdolrahimzadeh S, De Dominicis M, Mollo R. Sturge-Weber syndrome associated with nevus of Ota. Eye (Lond) 1998; 12: 212-213. 
7. Abdolrahimzadeh S, Scavella V, Felli L, et al. Ophthalmic alterations in the Sturge Weber syndrome, Klippel Trenaunay syndrome and the phakomatosis pigmentovascularis: an independent group of conditions? Biomed Res Int. 2015 Article ID 786519:11 pages.

8. Moe P, Seay AR. Neurologic and muscular disorders. In: Hay WW, Hayward AR, Levin MJ, Sondheimer JM, editors. Current Pediatric Diagnosis and Treatment, 16th edn. Singapore: McGraw Hill; 2003. p. 71792

9. Sinawat S, Auvichayapat N, Auvichayapat P, Yospaiboon Y, Sinawat S. 12-year retrospective study of Sturge-Weber syndrome and literature review. J Med Assoc Thai. 2014; 97(7): 742-750.

10. Sujansky E, Conradi S. Sturge-Weber syndrome: age of onset of seizures and glaucoma and the prognosis for affected children. J Child Neurol. 1995; 10: 49.

11. Abdolrahimzadeh S, Scavella V, Felli L, et al. Ophthalmic alterations in the Sturge Weber syndrome, Klippel Trenaunay syndrome and the phakomatosis pigmentovascularis: an independent group of conditions? Biomed Res Int. 2015 Article ID 786519:11 pages

12. Boniuk M. Hemangioma of the choroids. A clinicopathologic study of 71 cases and a review of the literature. Surv Ophthalmol. 1976; 20: 415-431. 